\title{
EDUCAÇÃO DE IMIGRANTES ALEMÃES EM CURTIBA
}

\section{Educación de imigrantes alemanes en Curitiba}

Valquiria Elita Renk ${ }^{1}$

\section{Resumo}

Este trabalho é o resultado da dissertação de Mestrado em Educação sobre a primeira Escola Alemã Católica de Curitiba, num período de 1896 até 1938. O período estudado envolve a época da sua fundação até o seu fechamento enquanto uma escola étnica. Investigamos por que esta adotava um padrão de escolaridade da Alemanha e só posteriormente adotou o padrão das escolas brasileiras. Destinava-se aos meninos desta etnia e posteriormente foi aberta aos meninos de outras etnias, inclusive os brasileiros e outros credos religiosos. Utilizamos como fontes de pesquisa as leis e decretos de Educação do Paraná e do Brasil, os jornais Diánio da Tarde e Der Kompass (A Bússola), que circularam durante o período estudado. Estas fontes nos permitiram reconstituir a trajetória histórica desta escola por meio da análise do seu cotidiano, das mudanças curriculares e do envolvimento comunidade étnica e religiosa e igreja.

Palavras-chaves: Escola alemã; História; Educação de imigrantes; Educação paranaense.

\section{Resumen}

Este trabajo de pesquisa científica es sobre la primera Escuela Alemana Catolica de Curitiba, en el periodo que va desde 1896 hasta 1938. Este tiempo es estudiado porvolver la epoca de su fundación hasta su cierramiento como una escuela de imigración. Vemos porque esta tuve un padrón de escolaridad de la Alemania e solamente en los años de 1930 es que el padrón fue convertido en el mismo padrón de las escuelas brasileñas. En su fundación solamente los niños alemanes es que podrian estudiar en la escuela pero

1 Doutora em Educação, Universidade Estadual de Maringá, Centro de Ciências Humanas, Letras e Artes, Departamento de Fundamentos da Educação - Av. Colombo, 5790, Zona 07, CEP: 87020-900, Maringá/PR

E-mail: crismach@mgalink.com.br 
después es que los niños brasileños fueram aceptos. Todo la enseñanza era en la lengua aleman como también se estudiava en lengua portuguesa. Las fuentes de pesquisa son las leyes de la educación de la Federación Brasileña y el Estado del Paraná, así como también los periódicos Der Kompassy Diario da Tarde. Con esas fuentes fue possible volver a la historia como un todo y entender los cambios de las leyes y de la educación en esa escuela de imigración.

Palabras-claves: Escuela alemana; História; Educación de imigrantes; Educación paranaense.

Este trabalho abordará a educação de um grupo de imigrantes muito específico: alemães católicos em Curitiba, no final do século XIX. Faz-se necessária esta ressalva, pois, em Curitiba, já havia pelo menos uma escola alemã constituída, mas de religião luterana.

O período deste estudo se estende de 1896 até 1938, quando analisamos a experiência étnica da "Katholishe Deutsche Volks-schule zu Curtitiba" (Escola Católica Elementar Alemã de Curitiba, atualmente Colégio Bom Jesus), fundada nos moldes das escolas da Alemanha, até seu fechamento enquanto escola étnica pelo Governo de Getúlio Vargas.

Esta escola atendia primeiramente este grupo étnico religioso, e assim, o seu currículo escolar era semelhante ao das escolas da Alemanha e não o padrão das escolas públicas brasileiras, com o ensino em língua alemã. Este grupo étnico trouxe a herança da escolaridade para os seus membros, no país de origem, desde o século XVIII. Ressalta-se aqui que esta escola também ensinava a língua portuguesa, pela necessidade deste grupo étnico de relacionar-se com a sociedade brasileira.

Chegando no Brasil, os imigrantes, no século XIX, não esperaram a ação do governo para as instalações de escolas para seus filhos. Criaram-nas com características de identificação com o país de origem, ensinando a língua materna e os costumes da Pátria distante. Estas escolas foram construídas e mantidas com o esforço das comunidades étnicas. No caso específico deste grupo étnico, o uso da língua alemã em casa, na imprensa, na igreja e na escola contribuiu para a manutenção de uma identidade cultural até a década de 1930. As associações culturais, mais a comunidade, a igreja e escolas, asseguravam uma relação intensa com a Alemanha. Na escola, as atividades curriculares e extracurriculares que asseguravam a manutenção das relações culturais com a pátria de origem, como o estudo da língua materna e o currículo com hinos, música, história e geografia da Alemanha.

Neste trabalho procuramos compreender a educação em uma escola de imigrantes com o suporte das Teorias da Etnicidade (POUTIGNAT; STREIFF-FENART 1998). Analisamos como este grupo utilizou e manipulou as cate- 
gorias étnicas que determinaram a emergência da identidade étnica, nas situações de contato com outros grupos étnicos. A visibilidade e a emergência da identidade étnica acentuou-se nos momentos de crise, como nas duas guerras mundiais do século XX.

Para este estudo, analisamos duas fontes documentais básicas: o jornal Der Kompass (A Bússola), publicado em língua alemã gótica, desde 1902 até 1941, pelos Padres Franciscanos de Curitiba e com o apoio de Professores do Colégio Bom Jesus e o Diário da Tarde, que circularam durante todo o período em estudo e também as Leis Educacionais desde 1900 até 1938 . O Diário da Tarde foi selecionado por ter tido uma existência que cobre todo o período em estudo, pois nesta época muitos outros periódicos iniciaram e saíram de a circulação. Quando analisamos as relações interétnicas, ressaltamos que é importante observar como os valores culturais significativos para os alemães foram preservados por um longo tempo, como a língua alemã, a religião católica e o associativismo, que são identificadores da cultura deste grupo étnico. A língua representou para os imigrantes alemães no Brasil o elemento mais marcante da identidade étnica. Ela era considerada como "a expressão por excelência do sangue e do espírito comuns (...). A língua humana significa muito mais do que uma mera forma de expressão. Ela brotou do sangue e da índole de um povo" (RAMBO, 1994, p. 45). No caso da língua alemã, ela assumiu a expressão da nacionalidade (Volkstum), ou seja, a perda da língua significa a perda desta identidade com os valores culturais da Pátriamãe, pois a nacionalidade alemã não se define pelo território.

A manutenção do ideal de pertencimento ao grupo alemão e do Deutschtum (etnicidade) se efetivou pelo uso da língua alemã cotidianamente e pela preservação dos valores culturais significativos para o grupo.

\section{A educação dos filhos dos imigrantes e a importância da etnicidade.}

A escola em estudo iniciou suas atividades como uma escola para um grupo de imigrantes muito específico. Posteriormente, abriu uma ala para alunos brasileiros e de outras etnias, dentro da mesma escola, com o ensino em língua portuguesa. Portanto, dentro da mesma unidade escolar havia duas escolas: a ala alemã e ala brasileira.

Na escola alemã, também se aprendia a língua portuguesa, pois nas relações com a sociedade brasileira, tinham de comunicar-se em português, mas, nas atividades do cotidiano e na vida privada poderiam comunicar-se em alemão. Aprender a língua portuguesa era uma necessidade política, pois fazia parte das obrigações da cidadania brasileira. Em Curitiba, por ser um centro 
urbano, industrial e comercial, as relações comerciais entre os dois grupos (alemães e brasileiros) eram muito intensas, daí mais uma necessidade de aprender a língua portuguesa.

O currículo das escolas alemãs, diferente das escolas públicas brasileiras, foi um elemento cultural que contribuiu com a manutenção da identidade étnica do grupo. 0 documento de fundação da escola em estudo citava que a língua alemã era parte do currículo e que à língua portuguesa também seria dada especial atenção. Conforme pudemos identificar, o primeiro currículo desta escola caracterizava-se por conter todas as matérias das escolas elementares da Alemanha, como Religião, Escrita, Leitura, Aritmética e Geometria, Língua Alemã, História Universal, Geografia Universal, Geografia, Ciência, Canto e Desenho, e também a Língua Portuguesa (ARNS, 1997, p. 19). O documento destaca que os professores eram formados em seminários e que já haviam lecionado na Alemanha ou no Brasil. Não bastava a escolaridade, era necessária uma escola dentro dos padrões de qualidade que o grupo considerava satisfatório.

Pelo jornal Der Kompass foi possível acompanhar a trajetória histórica do Bom Jesus, por meio do seu cotidiano, como as chamadas para matrículas, o início do ano letivo, as festas, comemorações, datas cívicas, visitas, celebrações, exames escolares e missas. Nesse processo pudemos analisar a manutenção da identidade étnica pelo grupo e a escola era um dos pilares, também a inserção deste grupo étnico na sociedade brasileira e as tensões decorrentes deste processo, nos perío dos das grandes guerras.

Desde a fundação da escola, até 1917, a ligação com a Alemanha era bastante expressiva, conforme o mesmo jornal registrou ano a ano. A exemplo disso podemos citar: a comemoração do aniversário do Imperador da Alemanha, seu Jubileu de Prata, as visitas do cônsul alemão à escola, comemoração de datas festivas e cívicas da Alemanha onde os alunos cantavam os Hinos Nacionais do Brasil e da Alemanha. O Der Kompass registrava cotidianamente os eventos que envolviam a comunidade étnica, a igreja e a escola. A relação com o país de origem tinha o papel de manter uma identidade cultural e estes traços culturais significavam diferença étnica.

A organização curricular também enfatizava a ênfase na manutenção da identidade étnica, por meio das disciplinas curriculares como 0 ensino da religião, da língua alemã, história universal e geografia, evidenciando-se a identidade com as escolas da Alemanha e não com a realidade brasileira. “(...) Além das matérias das Escolas Secundárias da velha Pátria, existe aqui o ensino dessas matérias em português, outro meio de alto valor formativo e importante para a vida prática" (ARNS, 1997). 


\section{A identidade étnica em confronto com a legislação educacional}

A legislação educacional do Paraná, desde o ano de 1900, enfatizava a necessidade do ensino da língua nacional nas escolas de imigrantes. A legislação educacional existente até 1938 versava sobre a necessidade da língua vernácula nas escolas, principalmente nas áreas de colonização estrangeira, pois as crianças estavam sendo alfabetizadas em língua estrangeira.

A necessidade de ensinar em língua portuguesa na legislação escolar foi pertinente com o sentimento de formação da nação brasileira. Portanto, para pensar em nação brasileira, era necessário que todos adotassem a mesma língua nacional. Daí a atenção especial nas áreas de imigração européia.

Para os governantes brasileiros, a língua nacional a ser falada em todo o país e ensinada em todas as escolas era um critério definido como formador da nação brasileira. Assim, para a formação da nação brasileira, era necessário que as escolas ensinassem a língua pátria e enfatizassem 0 ensino do Hino e da Bandeira Nacional, como também a história e a geografia do país.

Nas leis persistia a idéia de nação brasileira, tendo como suporte básico o uso da língua nacional e a não tolerância de línguas estrangeiras em território nacional. Em contrapartida, havia a luta dos imigrantes e seus descendentes em manter viva a identidade étnica, que implicava no uso da língua do país de origem.

A Lei Escolar n 365 de 11.04.1900, no Art. 20, enfatizava a obrigatoriedade do ensino da língua nacional. Na reformulação do ensino, por meio da Lei Estadual n. 923 de 03.04.1907, o ensino da língua portuguesa foi novamente colocado como obrigatória nas escolas.

O ensino da língua alemã e a manutenção da identidade cultural étnica manifestavam descontentamento da sociedade brasileira para com a comunidade alemã. A sociedade brasileira alertava sobre a formação de quistos étnicos no território brasileiro, o que denominava de "perigo alemão".

A Reforma do Ensino do Paraná, efetuada pela Lei 894 de 19.04.1909, abordava sobre a organização do ensino nas escolas particulares, trata o Título III, nos artigos 82 a 86, que mais uma vez reforçam a obrigatoriedade do ensino da língua nacional nas escolas primárias. Comparada com as legislações anteriores, esta era mais incisiva com a questão do ensino da língua nacional, estabelecendo multas para o não cumprimento deste artigo.

A escola Bom Jesus, no ano de 1908, já havia estabelecido um novo Plano escolar, com o acréscimo da disciplina de História do Brasil. Antes mesmo da eclosão da guerra, em 1910, período em que o perigo alemão era denunciado pela imprensa, a escola em estudo se autodenominava de escola bilíngüe, com o ensino em língua portuguesa e alemã. Apesar de ser conside- 
rada uma escola bilingüe, mantinha o nome (Deutsche Knabenschule - Escola de Rapazes) em alemão até 1938. O bilingüismo foi uma estratégia de sobrevivência, frente à situação de hostilidade enfrentada pelos alemães em Curitiba e também pode ser considerado como uma forma de manipulação das fronteiras étnicas, pois elas se "estendem ou se contraem em função da escala de inclusividade na qual se situam (...) e os traços culturais que demarcam a fronteira podem mudar" (POUTGNAT; STREIF- FENARt, 1998, p.158-195).

Os alunos também acompanhavam de perto as manifestações de hostilidade, como a da depredação da escola, durante a Primeira Guerra Mundial. Neste período os discursos nacionalistas proliferaram na imprensa brasileira. A exaltação à língua nacional e ao patriotismo estava presente em editoriais inflamados. No período de 1914-1918, a imprensa de Curitiba, em especial o Diário da Tarde, registrou os apelos em prol da nacionalização das escolas e das colônias étnicas.

As animosidades entre a sociedade brasileira e a comunidade alemã de Curitiba, no ano de 1917, foram marcadas por arruaças, ataques à Igreja, (principalmente aos padres e frades alemães) e à imprensa alemã. O controle social sobre as atividades desenvolvidas pela comunidade alemã foi rigoroso, principalmente no que se refere à escola étnica. O Colégio Bom Jesus também sofreu as conseqüências da guerra. Como no episódio em que os brasileiros cercaram a quadra do Bom Jesus, adentraram a Escola, saqueando, destruindo tudo e incendiando. Com ajuda da comunidade a mesma foi reconstruída.

Em 1917, com a entrada do Brasil na Guerra Mundial, a "Escola Alemã foi obrigada a fechar por vários meses, reabrindo em março de 1918, sendo-lhe, porém proibido ministrar aulas em alemão. Também os professores foram impedidos de lecionar" (PICCOLO, 1980, p. 21).

A campanha pelo uso da língua nacional nas escolas do Paraná ganhava cada vez mais adeptos, pois a manutenção da língua alemã nas escolas era considerada pelas autoridades como um processo de desnacionalização da infância. No Relatório do Secretário de Estado dos Negócios do Interior, Justiça e Instrução Pública, de 1917, está a afirmação textual do fechamento de quatro escolas estrangeiras e da disposição das autoridades em fechar aquelas que não cumprissem os dispositivos legais. Neste mesmo documento, o poder público tinha a competência de aprovar os programas das escolas particulares e o ensino de História, Geografia e Língua Portuguesa deveria ser ministrado por pessoas de competência reconhecida pelas autoridades. O nacionalismo era estimulado com o ensino de lições de patriotismo.

O Código de Ensino de 1917 que deu ênfase à propagação do ensino e à promoção de conferências sobre instrução pública. No Art. $4^{\underline{0}}$ estava estabelecida a competência do poder público em inspecionar os estabelecimentos particulares de ensino; difundi-lo e despertar o povo para a importân- 
cia da educação das crianças, por meio de conferências educativas e festas cívicas. $\mathrm{O}$ registro dos métodos de ensino e de toda a organização das escolas (públicas e particulares), a distribuição dos alunos pelas classes, os métodos pedagógicos, as matérias lecionadas e os livros adotados deveriam ser comunicados às autoridades. A idéia de nacionalidade também era objeto de estudo das disciplinas de Língua Nacional, Geografia e Corografia do Brasil e História do Brasil que enfatizavam as idéias de nação, país e os estudos formadores da moral e do civismo, com a conotação patriótica.

A comemoração das datas cívicas nacionais foi estimulada pelas autoridades. A política de nacionalização das escolas estrangeiras surtiu efeito. Após ter sido fechado em 1917, o Bom Jesus, reabriu em março de 1918. Também as relações com o país de origem foram modificadas, após a Primeira Guerra Mundial, comemorava-se o Dia do trabalho e o Dia da Bandeira Brasileira. Era uma escola bilíngüe, mas que não mantinha mais as relações com 0 país de origem, como até anteriormente ao ano de 1918.

Para formar o cidadão brasileiro, os programas escolares deveriam priorizar o ensino de História, Geografia, Moral e Cívica, estudos de Canto, Música e Declamação e também Ginástica e Esportes. Em 09 de abril de 1920, o Governador Caetano Munhoz da Rocha ampliou esta política, pela Lei $\mathrm{n}$. 2.005, estabelecia que as escolas estrangeiras eram obrigadas a ensinar em língua nacional e também História e Geografia do Brasil.

A necessidade de construir a nação brasileira por meio da escola era uma constante nas políticas educacionais. Na década de 20, o Relatório do Inspetor de Ensino, César Prieto Martinez, já informava ao governo sobre o perigo da desnacionalização da infância existente nas escolas estrangeiras. $\mathrm{O}$ mesmo informava que existiam inúmeras escolas onde não se ensinava a língua portuguesa e havia a proposta de uma campanha para convencer os colonos das vantagens da nacionalidade brasileira e da gratidão que deveriam ter para com o país que os acolheu. 0 mesmo fazia a proposta de fechamento das escolas estrangeiras no Paraná.

Prosseguindo no processo de nacionalização do ensino no Paraná, em 1922, o então Governador Munhoz da Rocha assinou o Decreto Lei n. 2.157, de 08 de abril, onde enunciava que o estabelecimento escolar deveria assumir o compromisso escrito de respeitar os feriados nacionais; ministrar ou fazer ministrar o ensino em vernáculo, salvo o das línguas estrangeiras e incluir no programa o ensino de Geografia, Corografia do Brasil por professores de reconhecida competência (....) (MARTINS, 1955, p. 386-387).

Nesta pode-se observar que o controle do Estado se tornava maior, incluindo o repasse por escrito das informações exigidas pela lei e novamente a necessidade do ensino de todas as disciplinas em língua portuguesa. Aparecem no texto da lei, de forma mais insistente, os ideários de formação da 
nação: só o ensino em língua nacional, a cultura da pátria, o ensinamento de elementos que tivessem valor simbólico como os hinos e a bandeira.

Apesar desta lei, as escolas estrangeiras ainda continuaram existindo no Brasil, tanto que o Colégio Bom Jesus não fechou suas portas e ainda manteve o nome em língua alemã - Deutsche Knabenschule. O rigor da legislação não poderia fechar uma escola que tinha uma ala inteira para a população nacional, ensinando em língua vernácula.

\section{A política de nacionalização do ensino e as tensões étnicas.}

O Governo Vargas tinha como premissa "erradicar as influências estrangeiras atuantes, principalmente nos três Estados do Sul e incutir nas populações de origem européia o sentimento de brasilidade" (SEYFERTH, 1982, p. 175). Pretendiam as autoridades a assimilação compulsória, por meio de uma legislação, que colocou à margem da lei as instituições consideradas estrangeiras, como as escolas, as sociedades assistenciais e a imprensa. Pode-se ler pelo texto da legislação a necessidade de ter uma identidade nacional única e, portanto, a não permissão de manutenção de identidade étnica diferenciada.

A educação também era entendida como um instrumento de nacionalização da população estrangeira e seus descendentes, principalmente do Sul do País e como fator de integração nacional. Neste contexto a educação moral e cívica teve especial relevância nos currículos escolares.

Na Constituição de 1937 ficava evidenciada a intenção da educação na formação do cidadão nacional, com um corpo saudável para o trabalho, disciplinado e com um sentimento de patriotismo. Assim, era preciso que as escolas de imigrantes também tivessem a mesma formação educacional voltada ao patriotismo e o mecanismo mais eficiente para isto foi a instituição de medidas nacionalistas e o fechamento das escolas estrangeiras.

\section{A extinção das escolas estrangeiras no Governo Vargas}

A situação de tensão entre o Governo Vargas e grupos étnicos se encaminhava para a extinção das escolas estrangeiras. Isto de fato ocorreu em 1938, com o Decreto Federal n. 406 de 04 de maio, conhecido como "Lei da Nacionalização". Esta lei enfatizava que:

todo o ensino fosse em língua portuguesa, que todos os professores e diretores fossem brasileiros natos, que nenhum livro de texto, revista ou jornal circulasse em língua estrangeira nos distritos rurais e que o currículo escolar 
deveria ter instrução adequada em história e geografia do Brasil (...) ( KREUTH, 1991, p. 154 ).

Esta lei proibia a publicação de revistas estrangeiras no meio rural, como uma forma de obrigar os colonos e seus filhos a falar e ler em português e também os livros didáticos deveriam ser escritos na língua nacional. Isto interferiu de forma fatal na organização das escolas alemãs, que tinham o material didático e a metodologia de ensino únicos.

A vida cotidiana nas escolas alemãs foi afetada com outras leis complementares e leis estaduais. O material didático e os livros escolares também foram censurados. No Decreto n.․ 1.545, de 15 de agosto de 1939, havia a instrução aos Secretários de Educação para que construíssem escolas públicas nas áreas de colonização estrangeira. Este decreto também determinava que o patriotismo deveria ser estimulado, a fiscalização ao ensino de línguas estrangeiras deveria prosseguir nas atividades cotidianas como também em assembléias e reuniões públicas; reafirmava que os estrangeiros não poderiam ser diretores e ainda, que a educação física fosse colocada sob a direção de um oficial das Forças Armadas. (Principalmente nos Art. 1.․ , 2.., , 3.․ 12 e 14).

O ensino de História e Geografia do Brasil era estimulado como uma maneira de formar uma nova geração de jovens, que não deveriam mais manifestar a sua origem étnica apenas à nacionalidade brasileira. $\mathrm{O}$ caráter disciplinador de nacionalização da História e da Geografia indicava claramente os objetivos políticos do Estado ao intensificá-las nos currículos escolares.

A Campanha Nacional de Nacionalização do Ensino radicalizou suas ações com o fechamento das escolas étnicas, principalmente as alemãs e japonesas. Kreutz (1991, p. 155) demonstra que à medida que as escolas étnicas foram fechadas, aumentou o número de escolas públicas que foram abertas. Assim, no Paraná, foram fechadas 78 particulares (estrangeiras) e abertas 70 escolas públicas. Nos Estados do Sul, São Paulo e Espírito Santo, a campanha da nacionalização fechou no período de 1937 até 1941, 774 escolas particulares, que foram substituídas por 885 escolas públicas, abertas nos mesmos locais, assim como também concedeu auxílio especial a esses Estados para a construção de prédios escolares nas comunidades de imigrantes (AZEVEDO, 1996, p. 678-679).

No Estado do Paraná, a política de nacionalização das escolas se efetivou pelo Decreto n. ${ }^{\circ} 6.149$ de 10.01.38, do Interventor Manoel Ribas. Esta lei também provou mudanças profundas na organização didática e pedagógica do Colégio Bom Jesus. Alguns professores se aposentaram, outros se naturalizaram e também houve a demissão de professores alemães, apesar de serem considerados muito competentes no seu ofício. "A escola passou pelo seu mais difícil transe" (ARNS, 1997, p. 115). Foi um momento muito difícil, 
pois era preciso explicar aos pais a situação e esperar que tivessem compreensão para com ela.

O Colégio Bom Jesus não fechou as portas, mas a escola alemã foi fechada, encerrando uma experiência de escola étnica. Portanto, a escola continua existindo até os dias atuais, como uma escola confessional. As duas alas da escola foram unificadas com o nome de Colégio Bom Jesus e todos os professores estrangeiros tiveram que se demitir.

A política nacionalista de Vargas extinguiu as escolas étnicas, acabando com esta experiência comunitária e étnica na história da educação brasileira.

\section{Referências}

ARNS, J. C. Uma escola centenária em sua moldura histórica. Curitiba: Linarth, 1997.

AZEVEDO, F. A cultura brasileira. 6. ed. Rio de Janeiro, RJ: Editora da UFRJ, 1996

KREUTZ, L 0 professor paroquial. Porto Alegre: EDUCS, 1991.

. Escolas da imigração alemã no Rio Grande do Sul. In: . Os Âlemães no sul do Brasil. Canoas: ULBRA, 1994.

MARTINS, W. Um Brasil diferente. São Paulo, SP: Anhembi Ltda, 1955.

POUTIGNAT, P.; STREIFF-FENART, J. Teorias da etnicidade. São Paulo, SP: Ed. UNESP, 1998.

PICCOLO, F. A. S. (org). História e estórias do Bom Jesus. Curitiba: Associação Franciscana de Ensino Senhor Bom Jesus, 1980.

SEYFERTH, G. A colonização alemã no Vale do Itajaí Mirim: um estudo do desenvolvimento econômico. Porto Alegre: Movimento, 1974.

. Nacionalismo e identidade étnica: a ideologia germanista e o étnico Teuto-Brasileiro numa comunidade no Vale do Itajaí. Florianópolis: F.C.C., 1981.

. Construindo a nação: hierarquias raciais e o papel do racismo na política de imigração e colonização. In: Janeiro, RJ: Fiocruz,1996.

. Raça, ciência e sociedade. Rio de 
. A identidade teuto-brasileira numa perspectiva histórica. In:

Os alemães no sul do Brasil. Canoas: ULBRA, 1994.

THOMPSON, E. A miséria da teoria ou um planetário de erros: uma crítica ao pensamento de Althusser. Rio de Janeiro, RJ: Zahar, 1981.

\section{Fontes Documentais}

BRASIL Decreto-Lei n. 406, de 04.05.1938. In Lex- Coletânea de Legislação. São Paulo: Lex Ed. Ltda,1938

BRASIL Decreto-Lei n. 1545, de 15.08.1939. In .Lex - Coletânea de Legislação. São Paulo: Lex Ed. Ltda, 1939.

JORNAL Der Kompass, de 1902 à 1937. Curitiba: Arquivo Colégio Bom Jesus. JORNAL Diário da Tarde. Curitiba. De 1914-1920 e de 1930-45. Biblioteca Pública do Paraná.

MARTINEZ, C. P. (Inspetor do Ensino) Relatório de Governo, 1920 e 1921. Curitiba: Tipografia da Penitenciária do Estado, 1920 e 1921. -DEAP

PARANÁ. Lei n. 894, de 19.04.1909. Curitiba: DEAP.

PARANÁ. Lei n. 723, de 03. 04.1907. Curitiba: DEAP.

PARANÁ. Lei n. 365, de 11.04.1900. Curitiba: DEAP.

PARANÁ. Decreto n.17, de 09.11.1917. Curitiba: Diário Oficial do Estado do Paraná, 10.01.1917. DEAP

PARANA. Relatório de Governo. Curitiba: Typ. Da Penitenciária do Estado: 1920 e 1921. DEAP

PARANÁ. Atos da Interventoria Federal no Estado. Curitiba: Diário Oficial Do Estado, 19.01.1938, 19.01.1938 e 22.03.1938.

Recebido em: 10/09/2004

Aprovado em: 30/11/2004 